\title{
A Cost-Efficient Charcoal-Based Adsorbent for Waste Water Treatment and Dye Removal
}

\author{
V. Aruna Janani, Anith Perera, S. Saravanan
}

\begin{abstract}
Activated charcoal derived from Moringa oleifera, Manihot esculanta, Carica papaya are efficient for waste water treatment and dye removal. Adsorption techniques are used to remove the non-bio degradable pollutants. The produced carbon was exemplified using Scanning Electron Microscopy and Fourier Infrared spectroscopy. The discoloration rate was higher at an optimum $\mathrm{pH}$ of 5 for all three samples and at an adsorbent dosage of $0.02 \mathrm{~g} / 100 \mathrm{ml}$ of effluent and the equilibrium was obtained in 10 minutes. Thus, the adsorbents have the prospective for realistic applications. Adsorption isotherms was evaluated by the Freundlich, Langmuir isotherms and higher linear attenuation coefficients showed that the experimental data shows a better fit to Freundlich model $\left(R^{2}=0.9987\right)$ for Manihot esculenta, Langmuir model for Carica papaya and Moringa oleifera $\left(R^{2}=0.9931\right)\left(R^{2}=0.9959\right)$. Kinetic studies were also executed for all the adsorbents and for Manihot esculenta data en suite well to pseudo-second order model $\left(R^{2}=0.9966\right)$, for Carica papaya $\left(R^{2}=0.9986\right)$ and for Moringa oleifera investigational data en suite well with Pseudo-first order $\left(R^{2}=0.9916\right)$ respectively.
\end{abstract}

Keywords: activated carbon, Carica papaya, Manihot esculenta, Moringa oleifera.

\section{INTRODUCTION}

Waste water is any water that has been affected by human use. It may consist of domestic effluents, industrial or commercial effluents, agricultural and sewer inflow or sewer infiltration. Therefore, waste water contains all the types of pollutants which include physical, chemical and biological pollutants. The contemporary era of expansion of technologies has seen an incredible raise in products leading to the damage of our ecosystem. Water pollution is one of the severe concerns caused by the impact of these technological growths. Dyes are one of the significant factors causative to water pollution. There are diverse categories of dyes like, acidic dyes, basic dyes, reactive dyes, azo dyes, etc. [1]. Manufacture of dyes has augmented due to their widespread use in textile industry [2]. There is a maximum of 0.7 million tons of synthetic dyes created as of dyeing operations out of which 200,000 to 280,000 tons are discharged into the environment [3]. Dyes that are liberated into water bodies are

Revised Manuscript Received on December 16, 2019.

* Correspondence Author

V. Aruna Janani*, Department of Chemical Engineering, Kalasalingam v.arunajanani@klu.ac.in

Anith Perara, Department of Chemical Engineering, Kalasalingam Academy of Research and Education, Krishnankoil, India. Email: anith22joe@gmail.com

S. Saravanan, Department of Chemical Engineering, Kalasalingam Academy of Research and Education, Krishnankoil, India. Email: saravanan.s@klu.ac.in Academy of Research and Education, Krishnankoil, India. Email:

tough to decline and due to their mutagenic nature, they have carcinogenic effects. Thus, controlling water pollution has turned into a serious issue in modern years $[4,5]$. Presently numerous researches have been carried out so as to treat chemical pollutants since it was found to be much more lethal. The impurities in the water can be removed using numerous conventional methods like precipitation, coagulation, absorption, photocatalysis, Ionization, Filtration etc. But all the above-mentioned techniques are found to be time consuming as well as expensive. Hence, we are in need to try some other techniques which can satisfy the current requirements.

Recently Adsorption plays a foremost part in the treatment of waste water. Frequently available natural adsorbents possess low cost, readily available, create less sludge and environmentally friendly. Hence, they are under higher consideration in the area of waste water treatment. In past studies adsorption has been conducted with Bio sorbents made from bentonite clay, wheat straw, barley husks, coconut shell, coir pith, apple pomace, corncobs, fly ash, etc. were found to be much more effectual than marketable activated carbon.

The objective of the current study is to conduct adsorption by activated charcoal produced from the stems of Morinja oleifera, Manihot esculenta, Carica papaya. The reasons for choosing these plants are they are easily available and are of low cost. Also, they contain soft wood which is fibrous and high in carbon content. In addition to this, they are rich in moisture content and therefore not used in paper and firewood. This makes them most suitable for waste water treatment and dye removal.

\section{MATERIALS AND METHODS}

\section{A. Adsorbent}

The stem of Carica papaya, Moringa oleifera, Manihot esculenta was gathered and then rinsed thoroughly with distilled water to get rid of some impurities from it Afterwards, washed wood was dried out to eliminate humidity content. Dried wood was activated with $0.1 \mathrm{~N}$ Sulfuric acid for 24 hours. After 24 hours, the wood was carbonized in the muffle furnace at a temperature of $700^{\circ} \mathrm{C}$ for 60 minutes. The prepared carbon particles are sieved with 60 mesh size. Sieving is done to increase the surface area of the carbon. The smaller the particle, the larger the surface area. Thus, activated carbon is synthesized. Adsorbate Methyl orange solution was made by dissolution of dye particle in distilled water. 


\section{A Cost-Efficient Charcoal-Based Adsorbent for Waste Water Treatment and Dye Removal}

\section{B. Experimental Protocol}

Material collection and processing.

The stem of Moringa oleifera, Manihot esculenta, Carica papaya were collected and rinsed with distilled water to take away the dirt from it. The washed wood was dried to remove the moisture content. The dried wood is activated using Sulfuric acid in order to improve the pore size. The wood was immersed in $0.1 \mathrm{~N}$ Sulfuric acid for 24 hours. After a time period of 24 hours, the wood was carbonized in the muffle furnace at a temperature of $700^{\circ} \mathrm{C}$ for 60 minutes. The prepared carbon particles are sieved with 60 mesh size. Sieving is done to increase the surface area of the carbon.[7] The smaller the particle, the larger the surface area. Thus, activated carbon is synthesized.

\section{Characterization}

Characterization is made so as to know the structure and the behavior of a substance. There are various methods of characterization of materials. In this study, FT-IR and SEM imaging are used to characterize the prepared activated carbon.

\section{RESULTS AND DISCUSSION}

\section{A. Scanning electron Microscope (SEM)}

SEM S-3000H (Hitachi, Japan) was used to determine the surface morphology. SEM analysis is an investigative technique to identify the topography of the sample under consideration. The high resolution of the microscope allows the user to evaluate the materials for their flaws or any contaminants that are present in the sample. The result of the SEM analysis before and after adsorption was given under magnification of $5.00 \mathrm{KX}$ and was shown in fig 1a) and 1b). It was evident that the rough of the sorbent before adsorption has been modified to smoother surface after adsorption.

\section{Fig.1a Before adsorption (Manihotesculenta)}

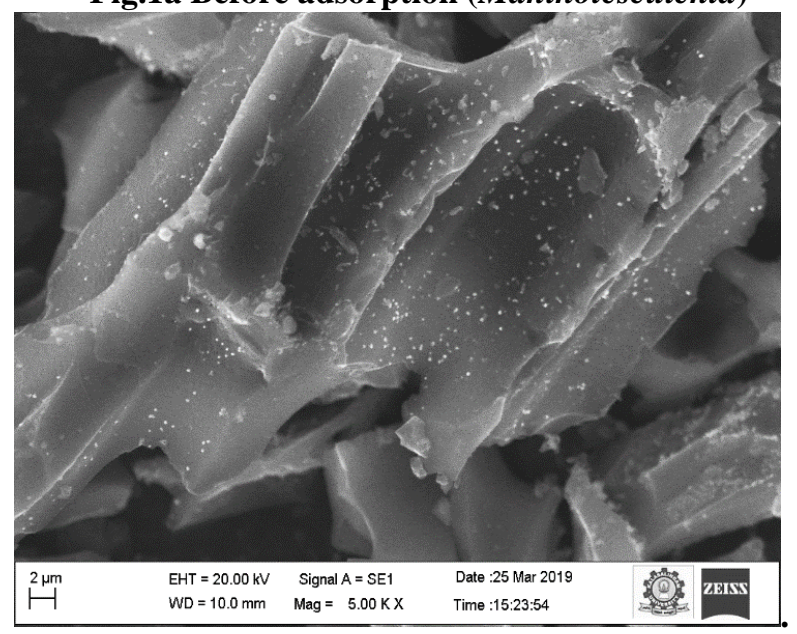

Fig. 1b. After adsorption (Manihot esculenta)

\section{B. FTIR analysis}

Graphs for all the three adsorbents (400- $4000 \mathrm{~cm}^{-1}$ ) confirm the adsorption. Adsorption bands shown in fig $2 \mathrm{a}$ ), 2b) and 2c) at 2890, 2990 $\mathrm{cm}^{-1}$ represent the presence of $\mathrm{C}=\mathrm{C}$ and $\mathrm{C}=\mathrm{O}$ stretching vibrations correspondingly. The peak position at $2890 \mathrm{~cm}^{-1}$ has become less intense after adsorption. This region has been assigned to $\mathrm{O}-\mathrm{H}$ stretching groups which interact with methyl orange dye. The FTIR spectrum of before and after dye adsorption was recorded using an RTracer-100, FTIR spectrophotometer (Shimadzu, Japan). These results are in accordance with the works accounted in literature [6].

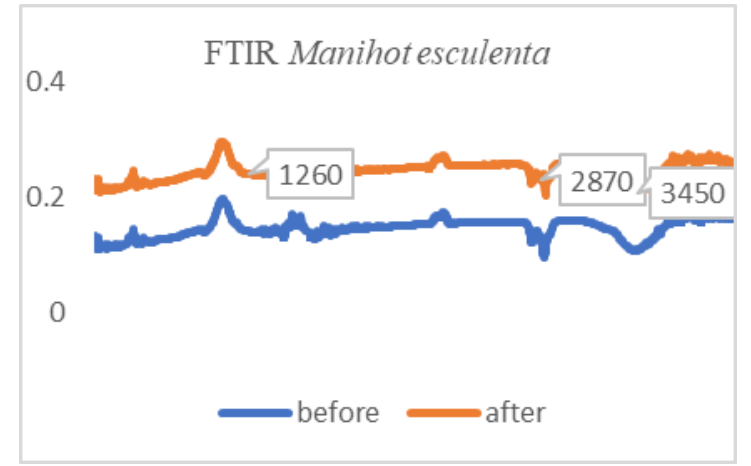

Fig.2a.

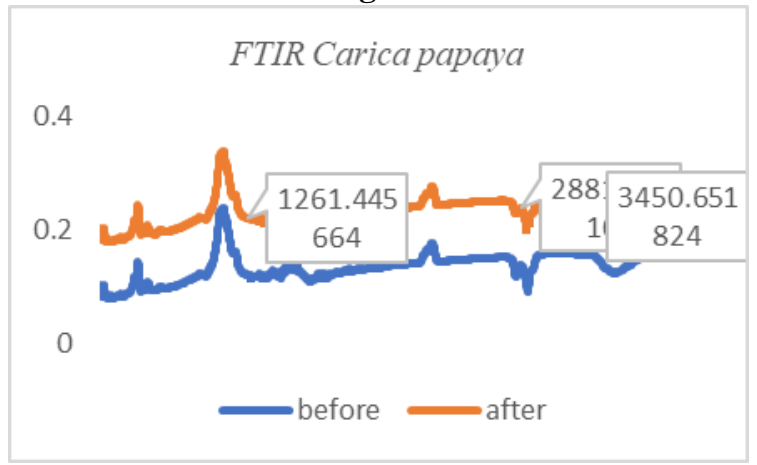

Fig. 2b.

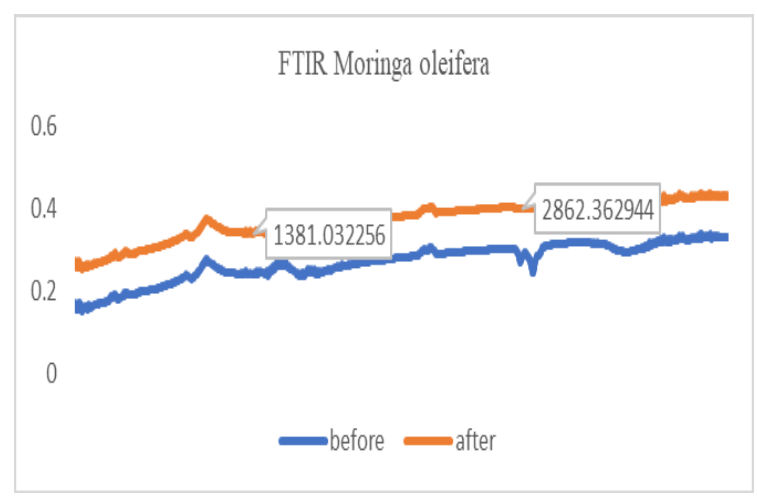

Fig. 2c.

Fig 2a), 2b) and 2c) FTIR data of Manihot esculenta, Carica papaya and Moringa oleifera before and after adsorption

\section{Point of Zero Charge}

The point of zero charge $\left(\mathrm{pH}_{\mathrm{pzc}}\right)$ is the key factor that determines the category of surface-active centres and the adsorption capacity of the chosen adsorbent [2]. In order to find out $\mathrm{pH}_{\mathrm{pzc}}, 0.02 \mathrm{~g}$ of adsorbent was included to $50 \mathrm{~mL}$ of $0.1 \mathrm{~N} \mathrm{NaCl}$. The $\mathrm{pH}$ of the solution was attuned from 2 to 11 using $0.1 \mathrm{~N} \mathrm{HCl} / 0.1 \mathrm{~N} \mathrm{NaOH}$. This solution was placed in shaker at $100 \mathrm{rpm}$ for a day after which the concluding $\mathrm{pH}$ of the solution was recorded $\left(\mathrm{pH}_{\mathrm{f}}\right)$. Graph is plotted between $\Delta \mathrm{pH}$ \{i.e. difference between initial $\left(\mathrm{pH}_{\mathrm{i}}\right)$ and final $\mathrm{pH}\left(\mathrm{pH}_{\mathrm{f}}\right)$ \} and initial $\mathrm{pH}\left(\mathrm{pH}_{\mathrm{i}}\right)$ [7]

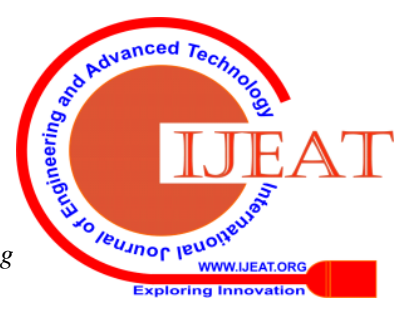


From fig 3) it is clear that anionic dye adsorption is favourable $\left(\mathrm{pH}<\mathrm{pH}_{\mathrm{pzc}}\right)$ owing to the occurrence of positively charged elements on the surface of the adsorbent. It is observed that the $\mathrm{pH}$ between 1 and 3 directs to the raise in the uptake capacity of adsorbents is high after which it begins to decrease. This is due to the fact that negatively charged ions in the dye solution are paying attention towards the electrostatic force of positively charged ions present on the surface of the adsorbent. Hence, anionic dye (methyl orange dye) adsorption takes place at lower $\mathrm{pH}$. Therefore, absorption of methyl orange dye is favourable at lower $\mathrm{pH}$. A similar tendency has been recorded in the literature by Jirekar et al. (2014) for methylene blue adsorption onto the surface of Phaseolus aureus [8].

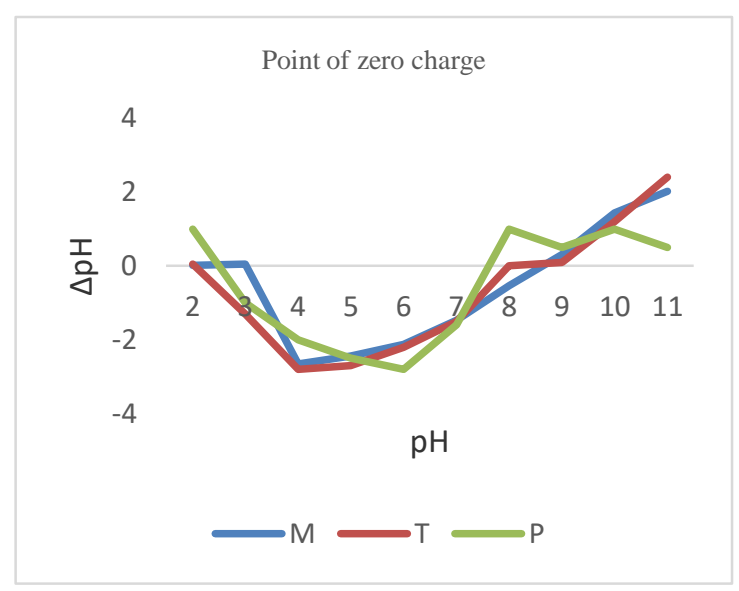

Fig.3. Point of zero charge of the adsorbents

D. Adsorption properties and batch adsorption studies The experiments were conducted as batch series. Methyl orange dye with a purity of $99.9 \%$ was purchased from Balaji Chemicals Ltd., Chennai, India to be used in the investigation. The dye stock solution (1000 $\mathrm{mg} \mathrm{L}^{-1}$ ) was prepared by dissolving a $\left(1 \mathrm{~g} \mathrm{~L}^{-1}\right)$ known amount of methyl orange dye in distilled water. The experimental solutions were acquired by diluting the stock solutions with distilled water to preferred concentration. Analytical grade chemicals and reagents used in this study were purchased from Merck, Mumbai, India. They were used as such without any further purification. The dyes from the effluent is adsorbed using the prepared activated carbon. $100 \mathrm{ml}$ of effluent is taken in a batch vessel and $0.02 \mathrm{~g}$ of carbon is used for the adsorption process. The initial absorbance of the effluent was noted for calculations. The setup was kept in a rotary shaker for better agitation of carbon with the effluent which promotes the adsorption process. The sample of $10 \mathrm{ml}$ was taken in an equal interval of 10 minutes and the samples were analyzed using UV-Vis spectrophotometer (UV- 2700 UV-Vis Spectrophotometer, Shimadzu, Japan) in order to measure the absorbance at a wavelength of $520 \mathrm{~nm}$. To ascertain the purpose of reproducibility of reported results, similar experiments were conducted and their standard deviations taken for further investigations. This is indicated by error bars representing the standard deviation of a data set which are incorporated in the figures.

\section{E. Parameters optimization \\ (i)Effect of $\mathrm{pH}$}

The $\mathrm{pH}$ of a dye solution is a significant persuading factor for the adsorption. The basic dye offers positively charged ions once dissolved in water. Sorption of the cationic adsorbate was opposed by the positively charged surface of sorbent in acidic medium. Once the $\mathrm{pH}$ of dye solution is improved the surface get hold of a negative charge, there by leading to raised adsorption of MB. Since the dye and adsorbent have positive and negative charges respectively, it leads to raise in the electrostatic attraction [9].

Experiments were conducted at different $\mathrm{pH}$ of 3, 5, 7 and 9 to find the effective $\mathrm{pH}$ at which the charcoal exhibits more adsorption occurs. Adsorbent were used at equal interval of $0.02 \mathrm{~g}, 0.04 \mathrm{~g}$ and $0.06 \mathrm{~g}$ per $100 \mathrm{ml}$ of effluent. The solution was experimented at different $\mathrm{pH}$ in the range from 3 to 9 for 60 minutes. The results from the fig 4) clearly show that the adsorption was maximum at $\mathrm{pH} 5$ and the lowest adsorption was found to occur at 3 for all the samples. By comparing to the results with other studies [10] which gives a maximum adsorption output at $\mathrm{pH}=8$ which is basic in nature but in this study the adsorption is greater in acidic solution in which it states the study can be extend to removal of azo dyes

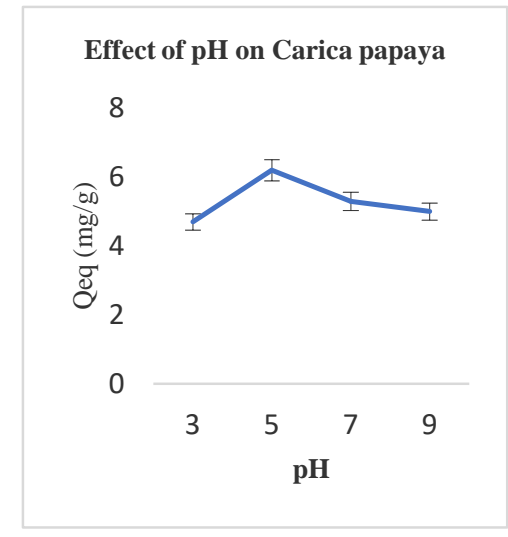

Fig. 4a.

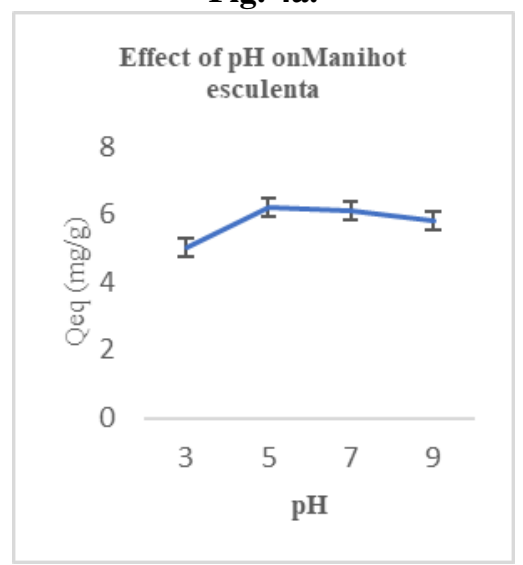

Fig.4b 


\section{A Cost-Efficient Charcoal-Based Adsorbent for Waste Water Treatment and Dye Removal}

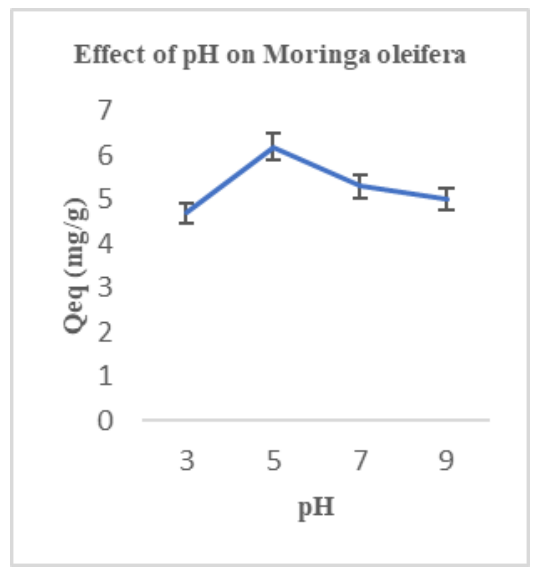

Fig.4c

Fig. 4a, 4b and 4c. Effect of pH on adsorption of dye using Manihot esculenta, Carica papaya and Moringa oleifera

(ii)Effect of adsorbent dosage

From the results, it can be concluded that as the quantity of bio sorbent increases, adsorption capacity starts to decrease. This is due to presence of more adsorption site as well as surface area at low sorbent dosage. Hence the sorption capacity was found to be more at the dosage of $0.01 \mathrm{~g} / 100 \mathrm{ml}$ fig 5). As the sorbent dosage increases above $0.01 \mathrm{~g}$ adsorption sites get saturated and resulted in agglomeration of biomass. Similar study shows absorbent dosage equilibrium at $0.001 \mathrm{~g} / \mathrm{L}$ [11] [12]

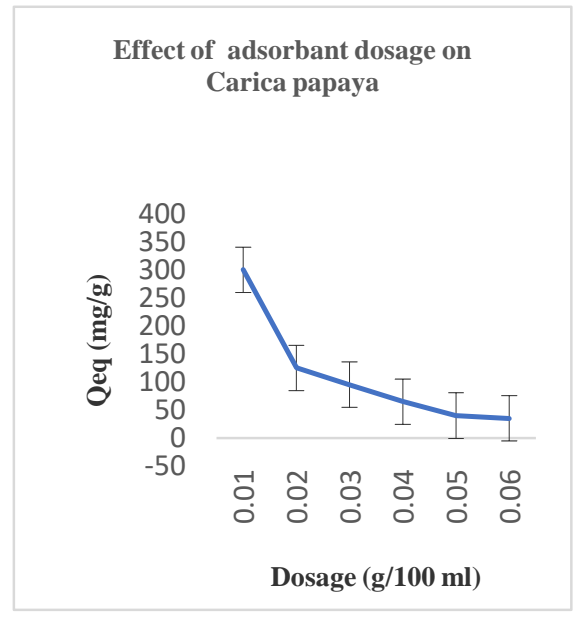

Fig. 5a.

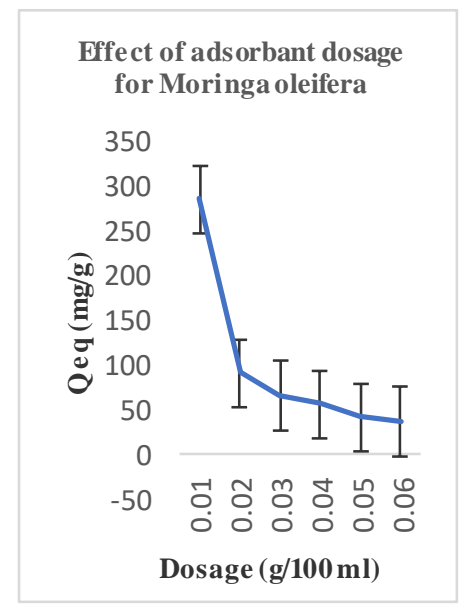

Fig. 5b.

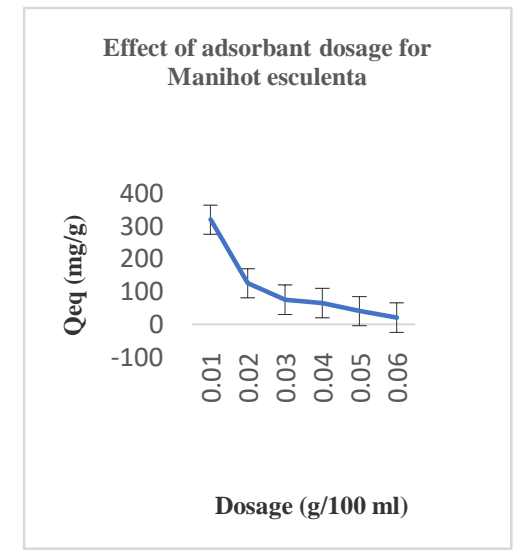

Fig. 5c

Fig. 5a, 5b and 5c. Effect of sorbent dosage on adsorption of dye using Manihot esculenta, Carica papaya and Moringa oleifera

(iii)Adsorption isotherm parameter studies

An adsorption isotherm can be described as the distribution of dye among solid and the solution when the equilibrium was reached. The Langmuir adsorption isotherm and Freundlich adsorption isotherm was chosen to verify the experimental data.

Langmuir adsorption isotherm

The Langmuir adsorption isotherm equation is stated below:

$$
\frac{\mathrm{C}_{\mathrm{e}}}{\mathrm{q}_{\mathrm{e}}}=\frac{1}{\mathrm{bQ}_{\mathrm{o}}}+\frac{\mathrm{C}_{\mathrm{e}}}{\mathrm{Q}_{\mathrm{o}}}
$$

where, $\mathrm{C}_{\mathrm{e}}$ is dye's equilibrium concentration of dye (mg $\left.\mathrm{L}^{-1}\right), \mathrm{q}_{\mathrm{e}}$ is the amount of dye adsorbed at the equilibrium time $\left(\mathrm{mg} \mathrm{g}^{-1}\right), \mathrm{Q}_{0}$ is the maximum amount of dye per unit weight of biomass at high $\mathrm{q}_{\mathrm{e}}$ and $\mathrm{b}$ is a constant which is related to the affinity of the binding sites. A plot of $\mathrm{C}_{\mathrm{e}} \mathrm{vs} \mathrm{C}_{\mathrm{e}}$ /qe gives a slope of $1 / \mathrm{Q}_{0}$ and an intercept of $1 / \mathrm{bQ}_{0}$. The following fig $\left.6 \mathrm{a}\right), 6 \mathrm{~b}$ ) and $6 \mathrm{c}$ ) shows the results of Langmuir model of adsorption isotherm. The linear attenuation co-efficient obtained by using this equation was obtained as $0.9931,0.9823,0.9959$ for Carica papaya, Manihot esculanta, Moringa oleifera respectively.

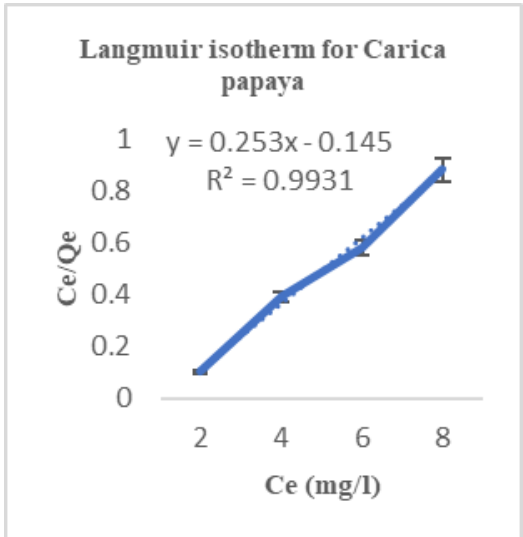

Fig. 6a. 


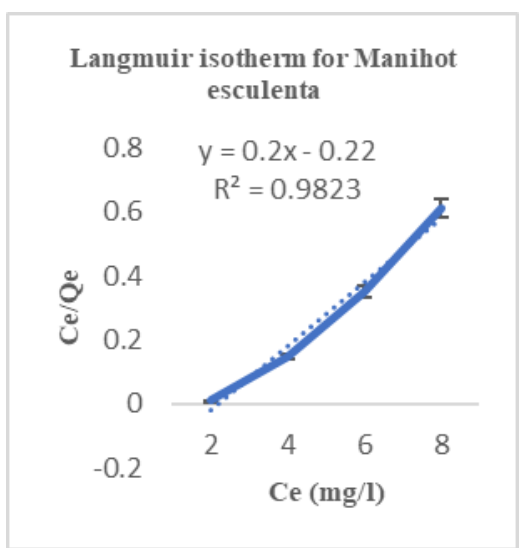

Fig. 6b.

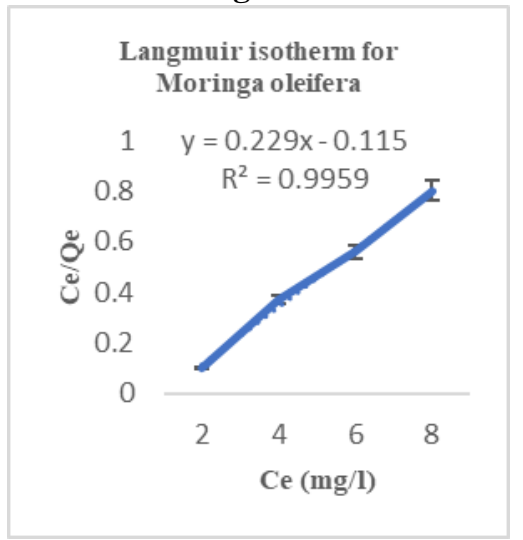

Fig. 6c.

Fig. 6a, 6b and 6c. Langmuir isotherm of Manihot esculenta, Carica papaya and Moringa oleifera

The Freundlich model is commonly used for the multilayer adsorption process as Langmuir model is used for a single layer adsorption. The expression that gives Freundlich isotherm is as follows:

$$
\ln \mathrm{q}_{\mathrm{e}}=\ln \mathrm{K}+\frac{1}{\mathrm{n}} \ln \mathrm{C}_{\mathrm{e}}
$$

where, $\mathrm{K}$ is adsorption capacity $\left(\mathrm{mg} \mathrm{g}^{-1}\right)$ and $\mathrm{n}$ is adsorption intensity. Plot can be drawn in order to find out the slope of $1 / \mathrm{n}$ and intercept of $\ln \mathrm{K}$. From the fig 7a), 7b) and 7c) it was found that this isotherm is fitted well to Manihot esculenta.

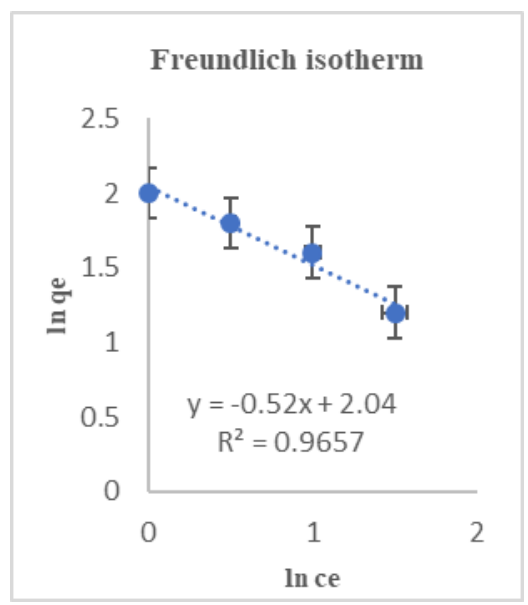

Fig. 7a.

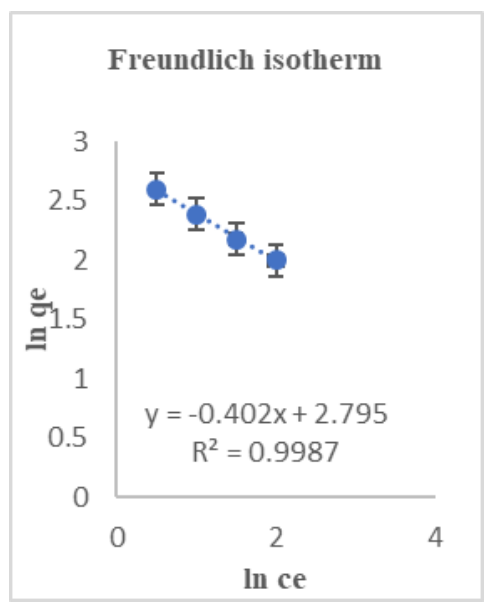

Fig. $7 b$.

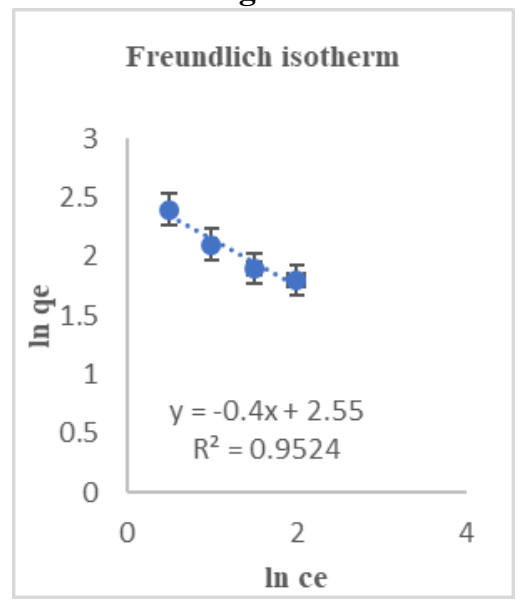

Fig. 7c.

Fig. 7a, 7b and 7c. Freundlich isotherm of Manihot esculenta, Carica papaya and Moringa oleifera

(iv Adsorption kinetics modelling

Adsorption kinetics modelling is performed to realize the method of adsorption process. By adsorption kinetics modelling we can determine the effectiveness of the adsorbent. In this case, the adsorption kinetics was determined using Pseudo first order, Pseudo second order.

Pseudo first order kinetic modeling

The Pseudo first order rate mode is given by the following equation:

$$
\log \left(\mathrm{q}_{\mathrm{e}}-\mathrm{q}_{\mathrm{t}}\right)=\log \mathrm{q}_{\mathrm{e}}-\frac{\mathrm{k}_{\mathrm{1}} \mathrm{t}}{2.303}
$$

where, qe is adsorption capacity at the equilibrium (mg $\left.\mathrm{g}^{-1}\right), \mathrm{q}_{\mathrm{t}}$ is adsorption capacity at any time $\left(\mathrm{mg} \mathrm{g}^{-1}\right)$ and $\mathrm{k}_{1}$ is pseudo-first-order rate constant $\left(\mathrm{min}^{-1}\right)$. A plot between $\mathrm{t}$ and $\log (\mathrm{qe}-\mathrm{qt})$ gives an intercept of loq (qe) and a slope of $\mathrm{k}_{1} /$ 2.303 which was shown in fig $8 \mathrm{a}), 8 \mathrm{~b}$ ) and $8 \mathrm{c}$ ). 


\section{A Cost-Efficient Charcoal-Based Adsorbent for Waste Water Treatment and Dye Removal}

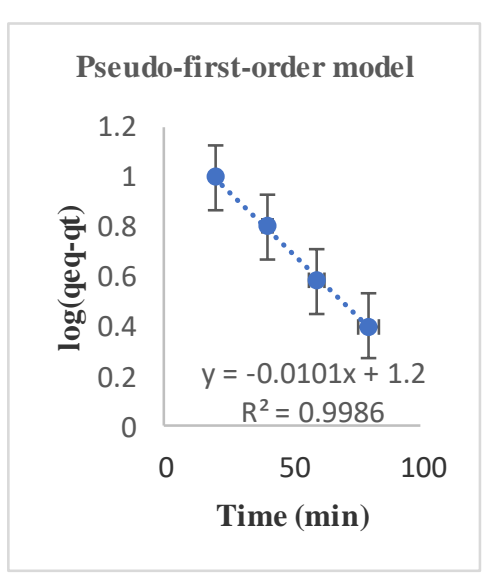

Fig. 8a.

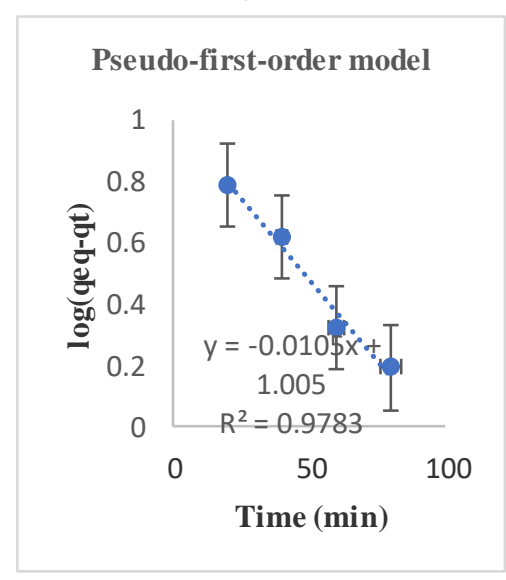

Fig. 8b.

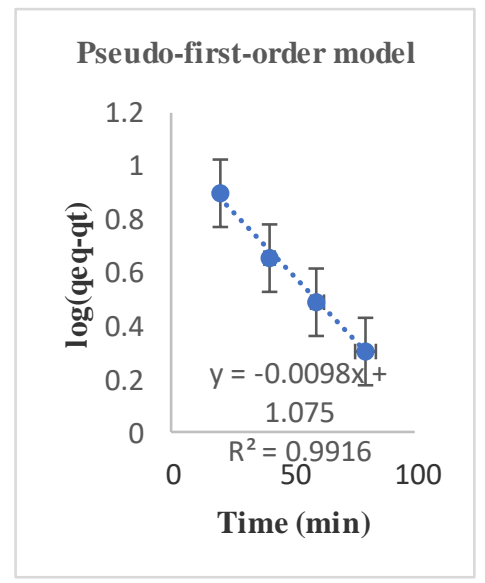

Fig. 8c.

Fig. $8 \mathrm{a}, 8 \mathrm{~b}$ and $8 \mathrm{c}$. Pseudo first order kinetic models of Manihot esculenta, Carica papaya and Moringa oleifera

Pseudo second order kinetic modeling

The Pseudo second order rate can be determined by using the below mentioned equation:

$$
\frac{t}{q_{t}}=\frac{1}{k_{2} q_{\mathrm{e}}{ }^{2}}+\frac{t}{q_{\mathrm{e}}}
$$

where, $\mathrm{q}_{\mathrm{e}}$ is adsorption capacity at equilibrium $\left(\mathrm{mg} \mathrm{g}^{-1}\right)$, $\mathrm{q}_{\mathrm{t}}$ is adsorption capacity of the adsorbent at any time $\left(\mathrm{mg} \mathrm{g}^{-1}\right)$ and $\mathrm{k}_{2}$ is the pseudo second order rate constant $\left(\mathrm{g} \mathrm{mg}^{-1} \mathrm{~min}^{-1}\right)$. The values of $k_{2}$ and $\mathrm{q}_{\mathrm{e}}$ can be identified from the fig $9 \mathrm{a}$ ), $9 \mathrm{~b}$ ) and $9 c)$ respectively.

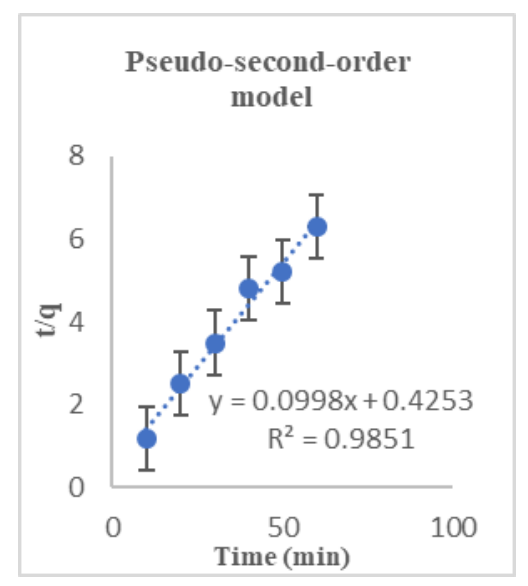

Fig. 9a.

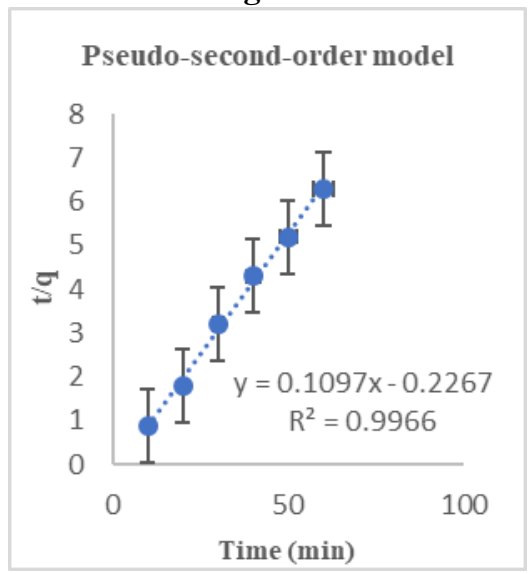

Fig. $9 b$.

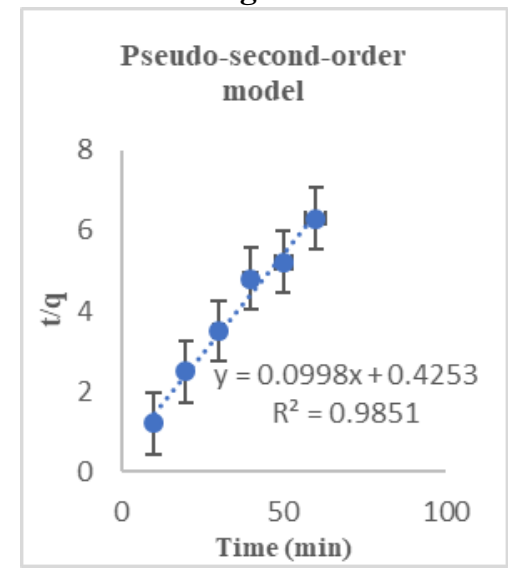

Fig. 9c.

Fig. 9a, 9b and 9c. Pseudo second order kinetic models of Manihot esculenta, Carica papaya and Moringa oleifera

\section{CONCLUSION}

The activated carbon from the wood of Carica papaya, Manihot esculenta, Moringa oleifera was successfully utilized as an valuable adsorbent for the elimination of the methyl orange from the aqueous solution and this process is also cost effective among the other techniques that are currently in practice. 


\begin{tabular}{|c|c|c|}
\hline Adsorbent & $q_{o}(m g g-1)$ & \\
\hline $\begin{array}{l}\text { Manihot esculenta stem activated } \\
\text { carbon* }\end{array}$ & 401.2 & $\begin{array}{l}\text { water by ads } \\
\text { agricultural } \\
\text { [13]. Annadurai } C\end{array}$ \\
\hline 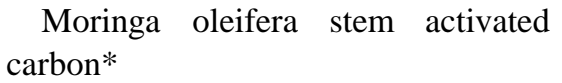 & 339.8 & $\begin{array}{l}\text { wastes fo } \\
\text { Mater., } 9\end{array}$ \\
\hline $\begin{array}{c}\begin{array}{c}\text { Carica } \\
\text { carbon* }\end{array} \\
\end{array}$ & 378.7 & $\begin{array}{l}\text { [14]. Kannan } \mathrm{N} \text {. } \\
\text { removal o } \\
\text { comparativ }\end{array}$ \\
\hline TIWAC [1] & 303.3 & [15]. H. N. B \\
\hline Coconut shell activated carbon [15] & 277.8 & \\
\hline Rice husk activated carbon [14] & 343.5 & \\
\hline Bamboo dust activated carbon [13] & 143.20 & \\
\hline Walnut shell activated carbon [13] & 3.53 & \\
\hline $\mathrm{NaOH}$ treated raw kaolin [13] & 16.34 & \\
\hline \multicolumn{3}{|l|}{ (* current study) } \\
\hline
\end{tabular}

. Namasivayam C. and Kavitha D. (2002). Removal of Congo Red from water by adsorption onto activated carbon prepared from coir pith, an solid waste. Dye Pigment., 54, 47-58. astes for adsorption of dyes from aqueous solutions. J. Hazard.

study. The SEM studies proved that there is difference in the surface morphology of the prepared carbon which confirmed that this synthetic dye was adsorbed onto the adsorbent. The adsorption isotherm parameters and the adsorption kinetics were also studied. The Freundlich isotherm was well fitted for Manihot esculenta and Langmuir isotherm for Carica papaya and Moringa oleifera with the experimental data and this process followed the Pseudo-first-order kinetic model for Carica papaya and Moringa oleifera and Pseudo-second-order kinetic model for Manihot esculenta.

\section{REFERENCES}

[1]. A. Kausar, M. Iqbal, A. Javed, K. Aftab, H. N. Bhatti and S. Nouren, Dye adsorption using clay and modified clay: A review, J. Mol. Liq., 265 (2018) 395-407.

[2]. A. Kanwal, H. N. Bhatti, M. Iqbal and S. Noreen, Basic dye adsorption onto clay/ $\mathrm{MnFe}_{2} \mathrm{O}_{4}$ composite: A mechanistic study, Water Environ. Res., 89 (2017) 301-311.

[3]. L. G. C. Villegas, S. Mazloum, K. E. Taylor and N. Biswas, Soyabean peroxidase- catalysed treatment of azo dyes with or without $\mathrm{Fe}^{\circ}$ pre-treatment, Water Environ. Res., 90 (2018) 675-684.

[4]. X. Xu, M. Tian, L. Qu and S. Zhu, Graphene oxide/chitosan/polyvinyl-alcohol composite sponge as effective adsorbent for dyes, Water Environ. Res., 89 (2017) 555-563.

[5]. P. Saravanan, P. Sivakumar, G. Geoprincy, G. N. Nagendra and S. Renganathan, Biosorption of acid green 1 using dried Rhodoturula glutinis biomass, Indian J. Environ. Prot., 32 (2012) 207-214.

[6]. F. Boudrahem, F. Aissani Benissad, A. Soualah, (2011) Adsorption of Lead(II) from Aqueous Solution by Using Leaves of Date Trees As an Adsorbent. Journal of Chemical \& Engineering Data, Vol 56: 1804-1812

[7]. V. Aruna Janani, S. Saravanan, S. Rajesh, P. Sivakumar, Sircar Anirbid (2018) Batch and column studies on the removal of methyl orange by Acalypha indica biomass using gravitational search algorithm as an optimization tool. Desalination and Water Treatment Vol. 147: 385-397.

[8]. Jirekar, A.A. Pathan and M. Farooqui, Adsorption studies of methylene blue dye from aqueous solution onto Phaseolus aureus biomaterials, Orient. J. Chem 30 (2014)1263-1269.

[9]. Abdelmajid Regti My Rachid Laamari (2017) 'The potential use of activated carbon prepared from Ziziphus species for removing dyes from waste waters"; Appl Water Sci (2017) 7:4099-4108 DOI $10.1007 / \mathrm{s} 13201-017-0567-8$

[10]. Deepak Pathania, Shikha Sharma, Pardeep Singh (2017) "Removal of methylene blue by adsorption onto activated carbon developed from Ficus carica bast"; Arabian Journal of Chemistry (2017) 10, S1445-S1451

[11]. P. Hettiarachchi, C.S.K. Rajapakse (2018) 'Tea industry waste activated carbon as a low cost adsorbant for methylene blue removal from wastewater' Research Journal of Chemical science Vol. 8(5), 7-18, May have received Best mentor award by AICTE for guiding students for Chhatra Vishwakarma Awards 2018. Apart from this I have also received awards from our own institute like Best Faculty Advisor award and Best Assignment Award.

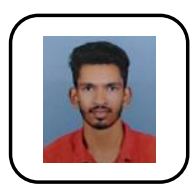

I am Anith Perera, Chemical engineering graduate from Kalasalingam Academy of Research and Education. I am a member of IIChE student chapter. have received awards from our institution for best lab with mini project

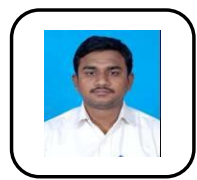

I am Dr. S. Saravanan, working as Associate Professor in the Department of Chemical Engineering for the past 3 years. I have completed my Ph.D. in NIT, Trichy. . My area of research is on treatment of industrial effluents using Advanced Oxidation processes. I have 4 publications in Scopus indexed journals. I am member in ISE.

I am V. Aruna Janani, working as Assistant Professor years. I have completed my B. Tech and M. Tech in Anna University. My area of research is on treatment of industrial effluents (Adsorption) using biosorbents. I have 